\title{
Anti-influenza virus effect of aqueous extracts from dandelion
}

Wen He $\mathrm{H}^{1,2,3}$, Huamin Han ${ }^{1,2}$, Wei Wang ${ }^{1,2}$ and Bin Gao ${ }^{1,4^{*}}$

\begin{abstract}
Background: Human influenza is a seasonal disease associated with significant morbidity and mortality. Anti-flu Traditional Chinese Medicine (TCM) has played a significant role in fighting the virus pandemic. In TCM, dandelion is a commonly used ingredient in many therapeutic remedies, either alone or in conjunction with other natural substances. Evidence suggests that dandelion is associated with a variety of pharmacological activities. In this study, we evaluated anti-influenza virus activity of an aqueous extract from dandelion, which was tested for in vitro antiviral activity against influenza virus type A, human A/PR/8/34 and WSN (H1N1).

Results: Results obstained using antiviral assays, minigenome assay and real-time reverse transcription-PCR analysis showed that $0.625-5 \mathrm{mg} / \mathrm{ml}$ of dandelion extracts inhibited infections in Madin-Darby canine kidney (MDCK) cells or Human lung adenocarcinoma cell line (A549) of PR8 or WSN viruses, as well as inhibited polymerase activity and reduced virus nucleoprotein (NP) RNA level. The plant extract did not exhibit any apparent negative effects on cell viability, metabolism or proliferation at the effective dose. This result is consistent with the added advantage of lacking any reported complications of the plant's utility in traditional medicine over several centuries.

Conclusion: The antiviral activity of dandelion extracts indicates that a component or components of these extracts possess anti-influenza virus properties. Mechanisms of reduction of viral growth in MDCK or A549 cells by dandelion involve inhibition on virus replication.
\end{abstract}

Keywords: Dandelion, Anti-influenza virus, Traditional Chinese Medicine

\section{Background}

Influenza A viruses are negative strand RNA viruses with a segmented genome that belong to the family of orthomyxoviridae. Both influenza A and B viruses can infect humans and cause annual influenza epidemics which result in significant mobidity and mortality worldwide. There are 16 hemagglutinin (HA) and 9 neuraminidase (NA) subtypes of the influenza A virus that infect a wide variety of species [1]. The introduction of avian virus genes into the human population can happen at any time and may give rise to a new pandemic. There is even the possibility of a direct infection of humans by avian viruses, as evidenced by the emergence of the highly pathogenic avian influenza viruses of the H5N1 subtype that were capable of infecting and killing humans [2].

\footnotetext{
* Correspondence: bgao2004@gmail.com

'CAS Key Laboratory of Pathogenic Microbiology and Immunology (CASPMI), Institute of Microbiology, Chinese Academy of Sciences, 1 Beichen West

Road, Beijing 100101, PR China

Full list of author information is available at the end of the article
}

Vaccines are the best option for the prophylaxis and control of a pandemic; however, the lag time between virus identification and vaccine distribution exceeds 6 months and concerns regarding vaccine safety are a growing issue leading to vaccination refusal. In the short-term, antiviral therapy is vital to control the spread of influenza. To date, only two classes of anti-influenza drugs have been approved: inhibitors of the M2 ion channel, such as amantadine and rimantadine, or neuraminidase inhibitors, such as oseltamivir or zanamivir [3]. Treatment with amantadine, and its derivatives, rapidly results in the emergence of resistant variants and is not recommended for general or uncontrolled use [4]. Among H5N1 isolates from Thailand and Vietnam, 95\% of the strains have been shown to harbor genetic mutations associated with resistance to the M2 ion channel-blocking amantadine and its derivative, rimantadine [5]. Furthermore, influenza B viruses are not sensitive to amantadine derivatives [6]. Recent studies have reported that the development of resistance can also occur against neuraminidase inhibitors

\section{() Biomed Central}


[7]. According to a recent study, oseltamivir-resistant mutants in children being treated for influenza with oseltamivir appear to arise more frequently than previously reported [8]. In addition, there are several reports suggesting that resistance in $\mathrm{H} 5 \mathrm{~N} 1$ viruses can emerge during the currently recommended regimen of oseltamivir therapy and that such resistance may be associated with clinical deterioration [9]. Thus, it has been stated that the treatment strategy for influenza A (H5N1) viral infections should include additional antiviral agents. All these highlight the urgent need for new and abundantly available anti-influenza agents.

A number of anti-flu agents have been discovered from Traditional Chinese Medicine (TCM) herbs. Ko et al. found that TCM herbal extracts derived from Forsythia suspensa ('Lianqiao'), Andrographis paniculata ('Chuanxinlian'), and Glycyrrhiza uralensis ('Gancao') suppressed influenza A virus-induced RANTES secretion by human bronchial epithelial cells [10]. Mantani et al. reported that the growth of influenza A/PR/8/34 (H1N1) (PR8) virus was inhibited when the cells were treated with an extract of Ephedraspp ('Mahuang') [11]. Hayashi et al. found that trans-cinnamaldehyde of Chinese cinnamon ('Rougui') could inhibit the growth of influenza A/PR/8 virus in vitro and in vivo [12]. Park et al. found that Alpinia Katsumadai extracts and fractions had strong antiinfluenza virus activity in vitro [13]. Many TCM herbs have been found to be anti-flu agents, but their mechanisms of action have not yet been elucidated [14,15].

Plants have a long evolutionary history of developing resistance against viruses and have increasingly drawn attention as potential sources of antiviral drugs [16,17]. Dandelion belongs to the Compositae family, which includes many types of traditional Chinese herbs [18]. Dandelion is a rich source of vitamins A, B complex, C, and D, as well as minerals such as iron, potassium, and zinc. Its leaves are often used to add flavor to salads, sandwiches, and teas. The roots can be found in some coffee substitutes, and the flowers are used to make certain wines. Therapeutically, dandelion has the ability to eliminate heat and toxins, as well as to reduce swelling, choleresis, diuresis, and inflammation [19]. Dandelion has been used in Chinese folklore for the treatment of acute mastitis, lymphadenitis, hepatitis, struma, urinary infections, cold, and fever. Choi et al. found that dandelion flower ethanol extracts inhibit cell proliferation and induce apoptosis in human ovarian cancer SK-OV-3 cells [20]. Hu et al. detected antioxidant, pro-oxidant, and cytotoxic activities in solvent-fractionated dandelion flower extracts in vitro [21]. Kim et al. demonstrated antioxidative, anti-inflammatory and antiatherogenic effects of dandelion (Taraxacum officinale) extracts in C57BL/6 mice, fed on an atherogenic diet [22]. Ovadje et al. suggested that aqueous dandelion root extracts contain components that induce apoptosis selectively in cultured leukemia cells, emphasizing the importance of this traditional medicine [23]. Furthermore, there are no side effects associated with the prolonged use of dandelion for therapeutic purposes.

In this report, we attempted to analyze whether dandelion have anti-influenza virus activity in cell culture. We found dandelion could inhibit the influenza virus infection. We further identified the inhibition of viral polymerase activity and the reduction of the virus nucleoprotein (NP) RNA level contributed to the antiviral effect. Thus, dandelion may be a promising approach to protect against influenza virus infections.

\section{Methods}

\section{Evaluation and extraction of plant materials}

Extracts made by boiling the herb in water. The voucher specimen of the plant material was deposited in the CAS Key Laboratory of Pathogenic Microbiology and Immunology (CASPMI), Institute of Microbiology, Chinese Academy of Sciences. Dandelion, purchased from a medicine store, was dissolved in sterile $\mathrm{H}_{2} \mathrm{O}(100 \mathrm{mg} / \mathrm{ml})$ at room temperature for $2 \mathrm{~h}$ and then extracted twice with water at $100^{\circ} \mathrm{C}$ for $1 \mathrm{~h}$. The aqueous extracts were filtered through a $0.45 \mu \mathrm{m}$ membrane. This aqueous dandelion extract lyophilized, and the resulting light yellow powder $(17 \% \mathrm{w} / \mathrm{w}$ yield) was dissolved with cell culture medium when needed.

\section{Viruses, cells and viral infections}

Human influenza virus A/Puerto Rico/8/34 (H1N1) (PR8) and A/WSN33 (WSN) were grown in 10-day old fertilized chicken eggs. After incubation at $37^{\circ} \mathrm{C}$ for 2 days, the allantoic fluid was harvested and used for infection.

All cell lines were purchased from ATCC (Rockville, MD, USA). Madin-Darby canine kidney (MDCK) cells or Human lung adenocarcinoma cell line (A549) were cultured in Dulbecco's modified eagle medium (DMEM) or RPMI-1640 medium, respectively, with $10 \%$ fetal bovine serum (FBS, Gibco, USA), penicillin $100 \mathrm{U} / \mathrm{ml}$, and streptomycin $10 \mu \mathrm{g} / \mathrm{ml}$. Prior to infection, the cells were washed with phosphate-buffered saline (PBS) and were cultured in infection medium (DMEM without FBS, 1.4\% BSA) supplemented with antibiotics and $2 \mu \mathrm{g} / \mathrm{ml}$ of trypsin (Gibco; Invitrogen, Carlsbad, CA).

\section{Hemagglutination inhibition test}

Influenza viruses are characterized by their ability to agglutinate erythrocytes. This hemagglutination activity can be visualized upon mixing virus dilutions with chicken erythrocytes in microtiter plates. The chicken erythrocytes were supplemented with $1.6 \%$ sodium citrate (Sigma, USA) in sterile water, separated by centrifugation $(800 \times \mathrm{g}, 10 \mathrm{~min}$, room temperature $)$ and washed three 
times with sterile PBS. Serial two-fold dilutions of dandelion extracts were made in $25 \mu \mathrm{l}$ of PBS in 96-well V-bottom plates. Influenza viruses in $25 \mu \mathrm{l}$ of PBS (4 HAU) were added to each dilution, and the plates were incubated for $1 \mathrm{~h}$ at room temperature. $25 \mu \mathrm{l}$ of $1 \%(\mathrm{v} / \mathrm{v})$ chicken erythrocytes in PBS was added to each well. The hemagglutination pattern was read following the incubation of the plates for $0.5 \mathrm{~h}$ at room temperature. The highest dilution that completely inhibited hemagglutination was defined as the hemagglutination inhibition (HI) titer.

\section{Cell viability assay}

A549 or MDCK cells were left untreated or treated with the indicated amounts of dandelion extracts ranging from 20 to $0.1563 \mathrm{mg} / \mathrm{ml}$, and oseltamivir ranging from 12.5 to $0.098 \mathrm{mg} / \mathrm{ml}$ for $48 \mathrm{~h}$; MDCK cells were left untreated or treated with $0.1 \mathrm{mg} / \mathrm{ml}$ oseltamivir, $2.5 \mathrm{mg} /$ $\mathrm{ml}$ and $15 \mathrm{mg} / \mathrm{ml}$ dandelion extracts for $72 \mathrm{~h}$. All drugs were multiproportion diluted in serum-free medium. Cell-proliferation and metabolism were measured using the CCK8-assay. Briefly, the cells were treated with CCK8 solution (dojindo, $10 \mu \mathrm{l} /$ well) and incubated for $4 \mathrm{~h}$ at $37^{\circ} \mathrm{C}$. The absorbance was measured using a microplate reader (DG5032, Huadong, Nanjing, China) at $450 \mathrm{~nm}$. The untreated control was set at $100 \%$, and the treated samples were normalized to this value according to the following equation: Survival rate (\%) = optical density (OD) of the treated cells - OD of blank control/OD of negative control - OD of blank control $\times 100$.

\section{Plaque titrations and antiviral assays}

Plaque titrations: MDCK cells grown to $90 \%$ confluency in 96-well dishes were washed with PBS and infected with serial dilutions of the supernatants in PBS for $1 \mathrm{~h}$ at $37^{\circ} \mathrm{C}$. The inoculum was aspirated and cells were incubated with $200 \mu \mathrm{l} \mathrm{DMEM} \mathrm{(medium} \mathrm{containing} \mathrm{1.4 \%} \mathrm{BSA,} 2 \mu \mathrm{g} / \mathrm{ml}$ of trypsin and antibiotics) at $37^{\circ} \mathrm{C}, 5 \% \mathrm{CO}_{2}$ for $2-3$ days. Virus plaques were visualized by staining with trypan blue.

Antiviral assay: MDCK cells were infected with the influenza A virus strain PR8 or WSN $\left(1 \times 10^{6}\right.$ PFU $)$ and were left untreated or treated with dandelion extracts (0.0782-5 $\mathrm{mg} / \mathrm{ml})$, oseltamivir (0.0047-0.3 mg/ml) (Sigma), or suxiaoganmaojiaonang $(0.069-4.375 \mathrm{mg} / \mathrm{ml})$. At $16 \mathrm{~h}$ post infection supernatants were taken. This procedure was repeated two times in triplicate. Supernatants were assayed for progeny virus yields by standard plaque titrations. Virus yields of mock-treated cells were arbitrarily set as $100 \%$.

Simultaneous treatment assay: dandelion extracts $(2.5$ $\mathrm{mg} / \mathrm{ml})$, oseltamivir $(0.1 \mathrm{mg} / \mathrm{ml})$ or suxiaoganmaojiaonang $(4.375 \mathrm{mg} / \mathrm{ml})$ was mixed with virus individually and incubated at $4^{\circ} \mathrm{C}$ for $1 \mathrm{~h}$. The mixture was inoculated onto near confluent MDCK cell monolayers $\left(1 \times 10^{5}\right.$ cells/well $)$ for $1 \mathrm{~h}$ with occasional rocking. The solution was removed, the cells were washed twice with PBS and the inoculum was aspirated, and then the cells were incubated with $2 \mathrm{ml}$ of DMEM supplemented with $1.4 \%$ BSA, antibiotics, $2 \mu \mathrm{g} / \mathrm{mL}$ trypsin at $37^{\circ} \mathrm{C}$ under $5 \% \mathrm{CO}_{2}$ atm.

Post treatment assay: Influenza viruses $\left(1 \times 10^{6} \mathrm{PFU}\right)$ were inoculated onto near confluent MDCK cell monolayers $\left(1 \times 10^{5}\right.$ cells/well) for $1 \mathrm{~h}$ with occasional rocking. The media was removed and replaced by DMEM containing $1.4 \% \mathrm{BSA}$, antibiotics, $2 \mu \mathrm{g} / \mathrm{mL}$ trypsin and dandelion extracts $(2.5 \mathrm{mg} / \mathrm{ml})$, or oseltamivir $(0.1 \mathrm{mg} /$ $\mathrm{ml})$, or suxiaoganmaojiaonang $(4.375 \mathrm{mg} / \mathrm{ml})$. The cultures were incubated at $37^{\circ} \mathrm{C}$ under $5 \% \mathrm{CO}_{2}$ atm.

After 6, 12, 24, 36 and $48 \mathrm{~h}$ incubation in all antiviral assays, the supernatant was analyzed for the production of progeny virus using the hemagglutinin test and was compared with the untreated control cells. Cell proliferation and metabolism were analyzed by the CCK8-assay at $48 \mathrm{~h}$ post-treatment. Virus yields from the mock-treated cells were normalized to $100 \%$.

\section{Real-time reverse transcription-PCR analysis}

MDCK cells were grown to about $90 \%$ confluence infected with influenza virus $\left(1 \times 10^{6} \mathrm{PFU}\right)$. Medium was removed after $1 \mathrm{~h}$, and cultured in the presence of dandelion extracts $(2.5 \mathrm{mg} / \mathrm{ml}) 13 \mathrm{~h}$. The inoculum was aspirated after 13 h. Cells were scraped off, washed twice with PBS, and collected by centrifugation ( $500 \mathrm{~g}$ for $5 \mathrm{~min}$ ). Total RNA was prepared using the RNApure total RNA fast isolation kit (Shanghai Generay Biotech Co., Ltd). The primer sequence used for quantitative real-time PCR of viral RNA were 5' -TGTGTATGGACCTGCCGTAGC - 3' (sense) and 5' - CCATCCACACCAGTTGACTCTTG - 3' (antisense). The Canis familiaris beta-actin was used as internal control of cellular RNAs, with primer sequences of 5' -CGTGCGTGACATCAAGGAAGAAG - 3' (sense) and reverse: 5' -GGAACCGCTCGTTGCCAATG - 3' (antisense). The primer sequences used in real-time PCR were designed using Beacon Designer 7 software.

Real-time reverse transcription-PCR was performed using $100 \mathrm{ng}$ of RNA and the One-step qPCR kit (RNAdirect SYBR Green Real-time PCR Master Mix, TOYOBO). Cycling conditions for real-time PCR were as follows: $90^{\circ} \mathrm{C}$ for $30 \mathrm{~s}, 61^{\circ} \mathrm{C}$ for $20 \mathrm{~min}$, and $95^{\circ} \mathrm{C}$ for 1 min, followed by 45 cycles of $95^{\circ} \mathrm{C}$ for $15 \mathrm{~s}, 55^{\circ} \mathrm{C}$ for $15 \mathrm{~s}$ and $74^{\circ} \mathrm{C}$ for $45 \mathrm{~s}$. As the loading control, we measured the level of Canis familiaris beta-actin mRNA. Real-time PCR was conducted using the ABI Prism 7300 sequence detection system, and the data were analyzed using ABI Prism 7300 SDS software (Applied Biosystems).

\section{Minigenome assay and transient transfection}

To test the transcription efficiency of the influenza virus polymerases after drug treatment, a minigenome assay 
was performed in Human embryonic kidney (293T) cells. Briefly, ambisense plasmids encoding PB2, PB1, PA and NP were cotransfected together with the influenza virus replicon reporter plasmid pPOLI-luciferase. The reporter plasmid pPOLI-luciferase was constructed by inserting the luciferase protein open reading frame (ORF) flanked by the noncoding regions of the $\mathrm{M}$ gene of influenza A virus between the BamHIand NotI site of the pPOLI vector (a generous present from Dr. Edward Wright). Calcuim phosphate transfection was used. Briefly, the cell culture was replaced by Opti-medium; $0.5 \mu \mathrm{g}$ of each plasmid was mixed, incubated at room temperature for $15 \mathrm{~min}$, and added over $80 \%$ confluent $293 \mathrm{~T}$ cells seeded the day before in six-well plates. Six hours later, the DNA-transfection mixture was replaced by DMEM containing $10 \%$ FBS. At $48 \mathrm{~h}$ posttransfection, the cells were treated with cell lysis buffer, centrifuged, and supernatant was collected. Add $5 \mu \mathrm{l}$ aliquots of cell lysate to individual luminometer tubes containing $180 \mu \mathrm{l}$ of luciferase assay buffer at room temperature. To start the assay, inject $100 \mu \mathrm{l}$ of luciferin solution into the luminometer tube and measure the light output in the luminometer.

\section{Statistical analysis}

Data were presented as mean $\pm \mathrm{SD}$. The data were statistically evaluated using a one-way ANOVA to compare differences between the groups. A p-value of $<0.05$ was considered to be significant. The IC50 and CC50 values were calculated using GraphPad Prism programme.

\section{Results}

Treatment with aqueous dandelion extracts results in a reduction of progeny virus titers

Treatment with aqueous dandelion extracts results in an efficient and concentration-dependent reduction of progeny virus titers in infected lung epithelial cells (A549) or Madine-Darby canine kidney (MDCK) cells; both of which are standard host cell lines for influenza virus propagation. These cells were treated with dandelion extracts at various concentrations $(0.0782-5 \mathrm{mg} / \mathrm{ml}) 1 \mathrm{~h}$ post-infection with different influenza A virus strains, including human prototype isolate A/Puerto-Rico/8/34 (PR8) and A/WSN33 (WSN) (H1N1). The concentrations of the plant extract dilutions were kept constant in each sample throughout the experiment and showed a dose-dependent change in virus titer. Oseltamivir $(0.0047-0.3 \mathrm{mg} / \mathrm{ml})$ was used as a positive control and suxiaoganmaojiaonang $(0.069-4.375 \mathrm{mg} / \mathrm{ml})$ was used as a negative control for the inhibition of virus replication (Figure 1). The maximum inhibitory effect $(100 \%)$ was obtained with $5 \mathrm{mg} / \mathrm{ml}$, and the $\mathrm{IC}_{50}$ of dandelion extracts was $0.99 \mathrm{mg} / \mathrm{ml}$.
Dandelion treatment does not affect cell morphology, viability, or negatively interfere with proliferation and metabolism

A major prerequisite for an antiviral agent is safety. Thus, we tested whether therapeutic concentrations of dandelion extracts would have any harmful effects on healthy cells. Initially, cells treated with dandelion extracts at the indicated concentrations were examined for changes in morphology. No differences in cell shape or cell number could be observed compared with untreated control cells. The same cells were treated with the CCK- 8 solution to detect cell proliferation and metabolism in each sample (Figure 2). The $\mathrm{CC}_{50}$ of dandelion extracts was $8.47 \mathrm{mg} / \mathrm{ml} . \mathrm{SI}=\mathrm{CC} 50 / \mathrm{IC} 50=8.47 /$ $0.99=8.4$.

\section{Inhibitory activity of dandelion extracts on influenza virus replication}

The post treatment assay was performed to evaluate whether dandelion extracts are able to inhibit replication of influenza virus A/PR/8/34 and WSN (H1N1) in MDCK cells. Dandelion showed a strong antiviral activity against $\mathrm{A} / \mathrm{PR} / 8 / 34$ and WSN (H1N1) at concentration $2.5 \mathrm{mg} / \mathrm{mL}$ (Figure $3 \mathrm{~B}$ ).

\section{Dandelion extracts does not block the hemagglutination activity of pre-treated virus particles}

To determine whether dandelion extracts would prevent the ability of virus particles to bind to cell surface receptors, we used simultaneous treatment assay and hemagglutination inhibition (HI) assays. The simultaneous treatment assay results indicated that treatment with dandelion extracts on virus entry couldn't inhibit virus infectivity (Figure 3A). Influenza A viruses are able to agglutinate red blood cells (RBCs) by means of hemagglutinin, a viral glycoprotein that binds to $\mathrm{N}$-acetylneuraminic acid at the cell surface. The RBCs become cross-linked by the virus and will form a type of lattice. This cross-linking results in a diffuse distribution of the RBCs in a roundbottom vial, as compared with the spot-like appearance of RBCs in the absence of any virus. Pretreatment with dandelion extracts could not prevent the binding of different viruses to RBCs in this assay (Figure 4). These findings suggest that aqueous dandelion extracts do not block binding of viruses to cell receptors by directly interfering with viral $\mathrm{HA}$.

\section{Viral RNA synthesis is affected in the treatment of dandelion extracts}

The levels of influenza viral RNA were compared between dandelion extracts -treated and untreated infected cells. RNA extraction was performed at $16 \mathrm{~h}$ after influenza virus infection and the levels of intracellular influenza 


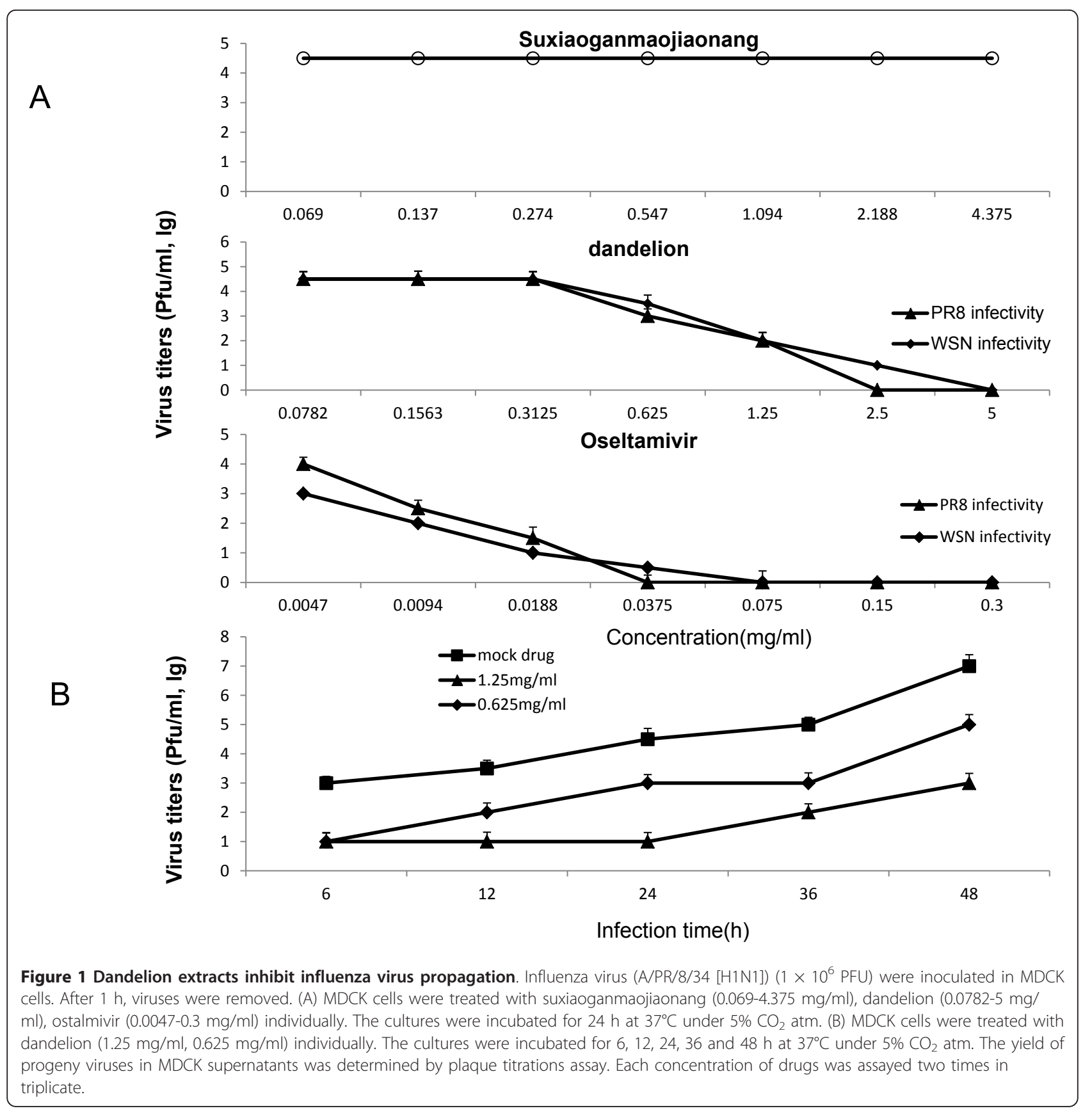

RNA were measured. Quantitative real-time PCR showed a reduction of influenza RNA from dandelion extracts $(2.5$ $\mathrm{mg} / \mathrm{mL}$ ) treated cells comparison with the non-treated cells in both A/PR/8/34 (H1N1) and WSN. There were marked differences in NP RNA level between dandelion extracts-treated virus-infected cells and untreated virusinfected cells (Figure 5). These results indicate that blockage of virus replication is one of mechanisms, by which dandelion exerts antiviral effects.
Treatment with dandelion extracts inhibit viral polymerase activity

To evaluate if dandelion extracts influenced the polymerase activity, we performed a flu minigenome reporter assay (Figure 6A). The flu minigenome plasmid containing the luciferase reporter gene was cotransfected into 293T cells together with the four plasmids necessary for viral polymerase activity (PB2, PB1, PA and NP). The luciferase expression was quantified as 


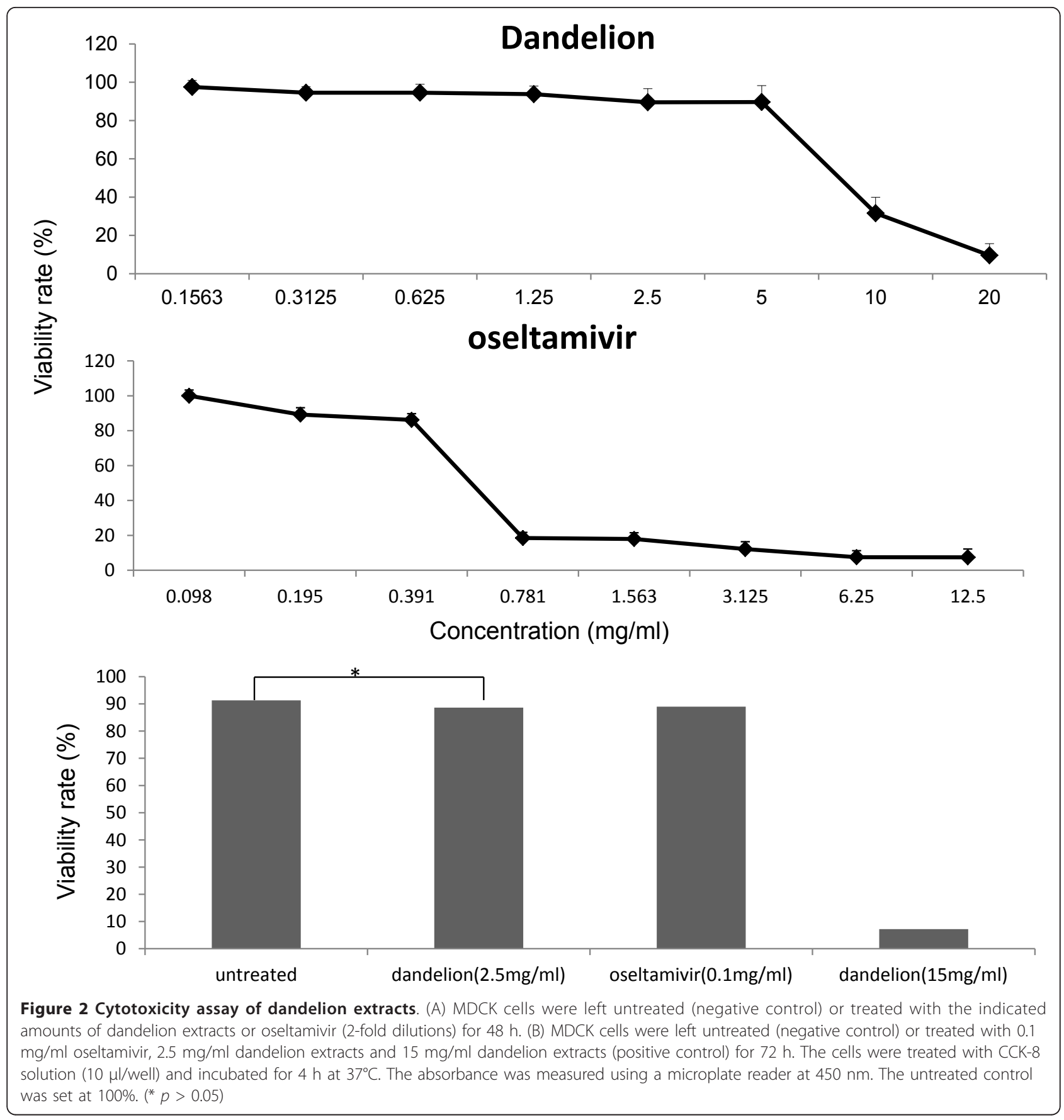

described in Materials and Methods. There were marked differences between dandelion extracts treated virusinfected cells and non-treated or ostalmivir treated virus-infected cells (Figure 6B). These results indicate that dandelion inhibited the viral polymerase activity, then to exert antiviral effects.

\section{Discussion}

Outbreaks of avian $\mathrm{H} 5 \mathrm{~N} 1$ pose a public health risk of potentially pandemic proportions. Infections with influenza A viruses are still a major health burden, and the options for the control and treatment of the disease are limited. Natural products and their derivatives have, historically, been invaluable sources of therapeutic agents. Recent technological advances, coupled with unrealized expectations from current lead-generation strategies, have led to renewed interest in natural products in drug discovery. This is also true in the field of anti-influenza research [24]. Here, we show that aqueous dandelion extracts exert potent antiviral activity in cell culture. 


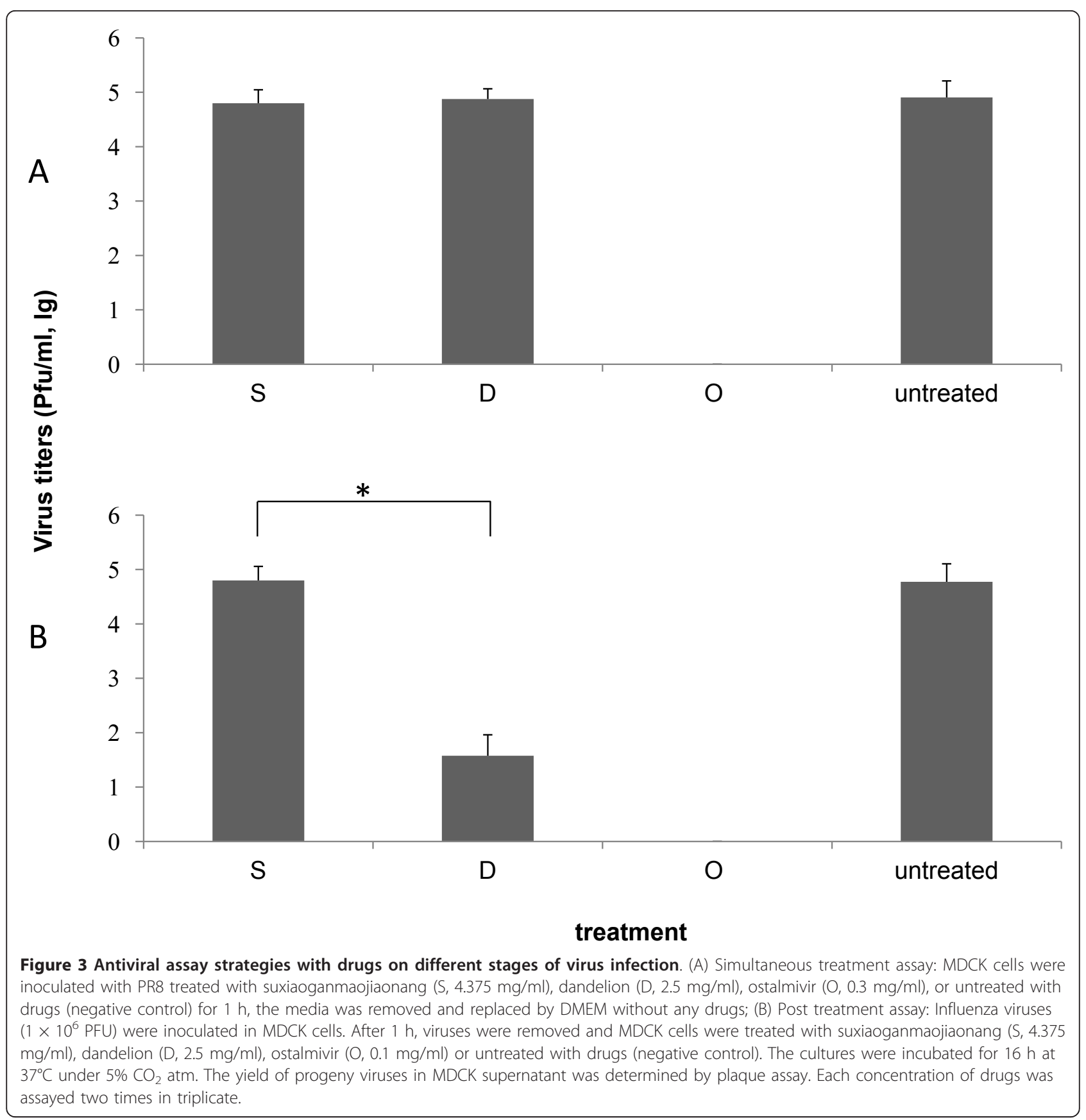

Dandelion is a natural diuretic that increases urine production by promoting the excretion of salts and water from the kidney. Dandelion extracts may be used for a wide range of conditions requiring mild diuretic treatment, such as poor digestion, liver disorders, and high blood pressure. Dandelion is also a source of potassium, a nutrient often lost through the use of other natural and synthetic diuretics. Additionally, fresh or dried dandelion herb is used as a mild appetite stimulant and to improve stomach symptoms, including feelings of fullness, flatulence, and constipation. The root of the dandelion plant is believed to have mild laxative effects and is often used to improve digestion.

Dandelion has a very high polyphenol content [18]. It is well known that polyphenols have protein-binding capabilities, which suggests that components of dandelion extracts may interact with pathogens through physical, non-specific interactions. Two potential advantages of this non-specific mechanism of action may be that resistant variants only emerge rarely and that dandelion 


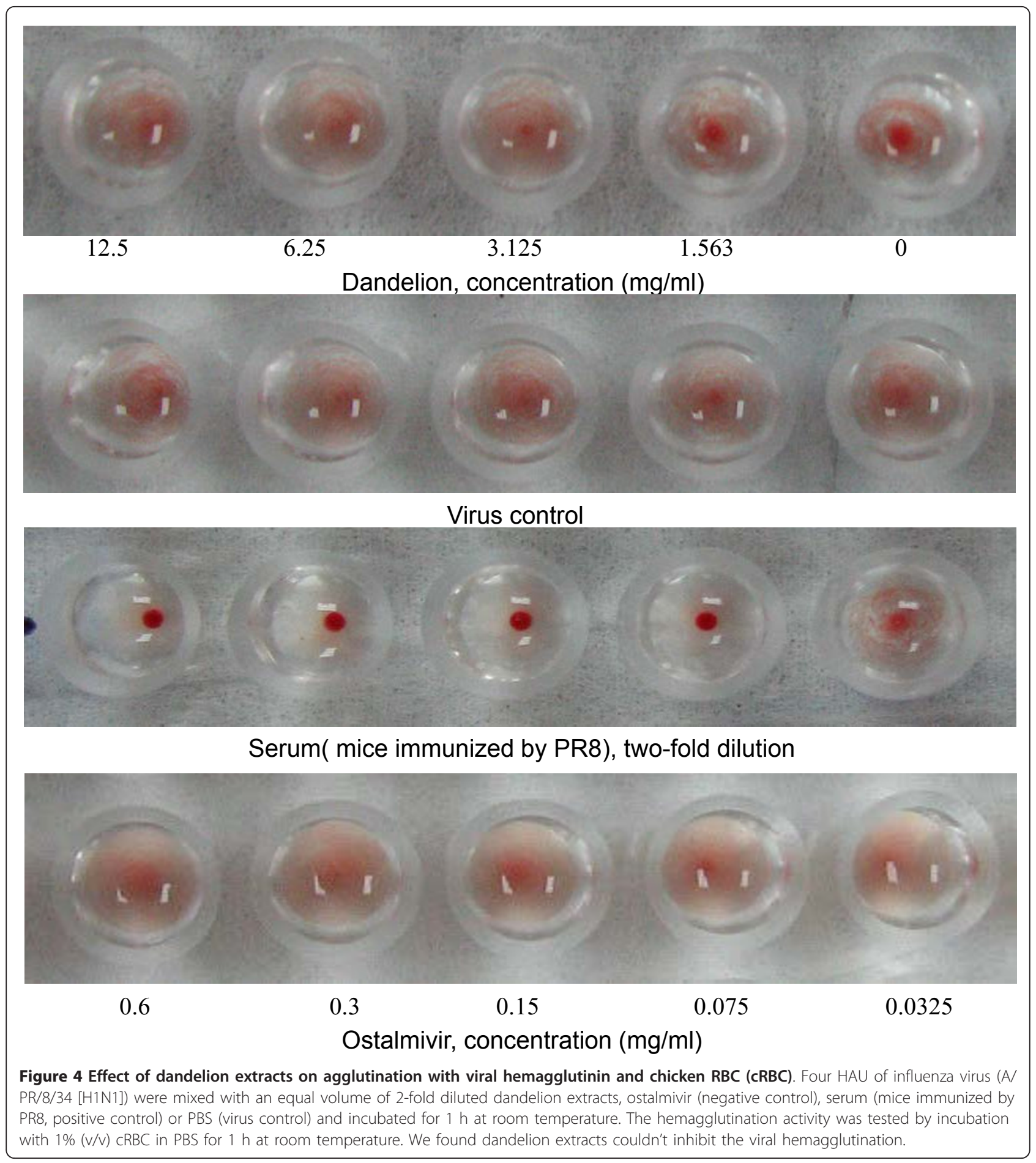

extracts may also act against bacterial co-infections that represent a major complication in severe influenza virus infections. A non-specific interaction with viral HA has been reported for the polyphenolic compound epigallocatechin-gallate [17]. Simultaneous treatment was used to identify whether dandelion extracts block the viral adsorption to cells. The simultaneous treatment assay did not show significant antiviral activity (Figure 3A). These data indicate that dandelion extracts can not directly interfere with viral envelope protein at the cell surface. Therefore, we used HI assays to determine whether dandelion extracts interacted with HA of influenza virus (Figure 4). Dandelion extracts did not exhibit inhibition of viral $\mathrm{HA}$ in both $\mathrm{A} / \mathrm{PR} / 8 / 34$ and WSN 


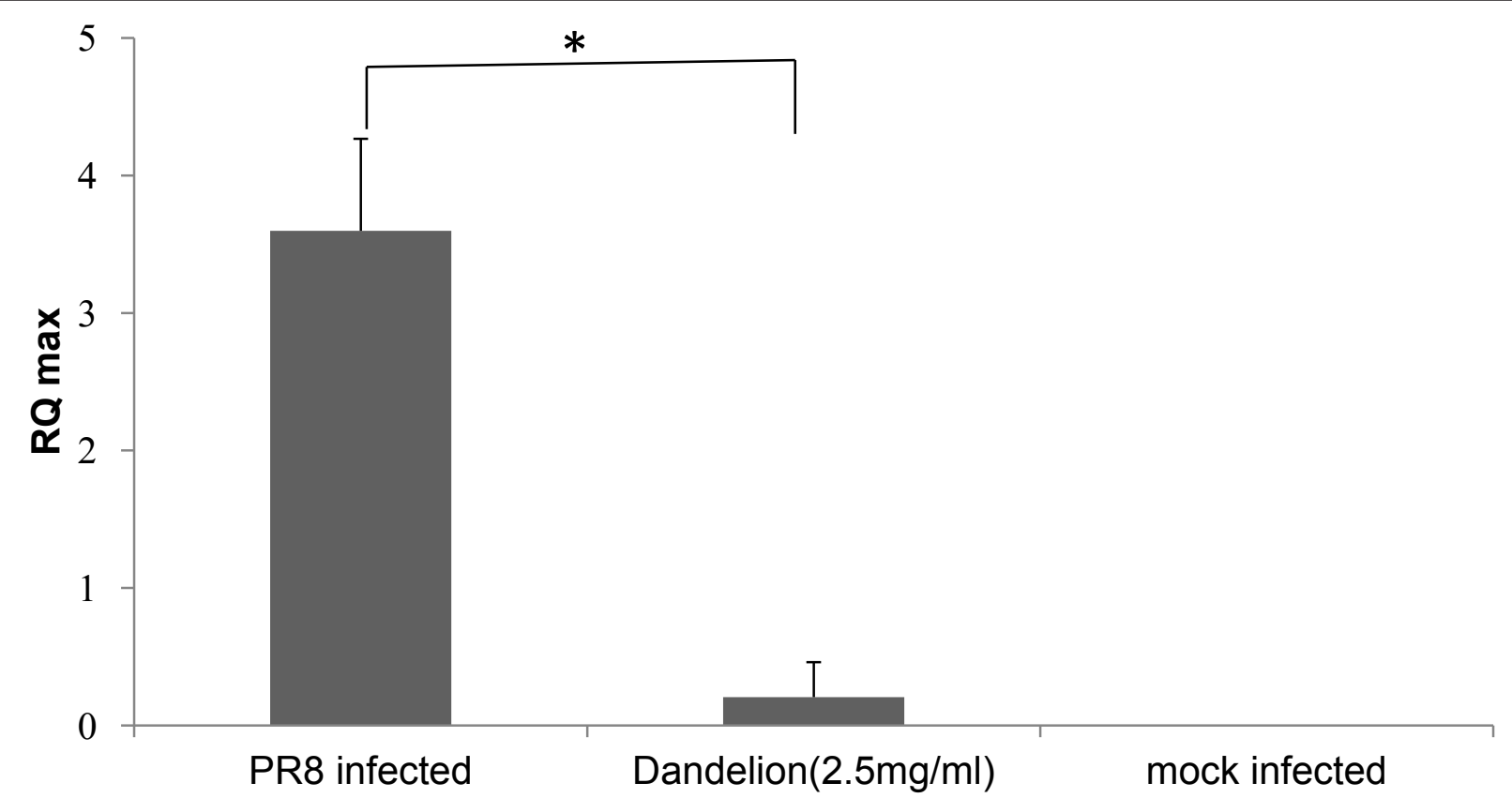

Figure 5 Real-time reverse transcription-PCR of influenza viral Nucleoprotein (NP) RNA levels normalized to beta-actin. MDCK cells were infected with influenza viruses A/PR/8/34 (H1N1) $\left(1 \times 10^{6} \mathrm{PFU}\right)$. After $1 \mathrm{~h}$, viruses were removed. MDCK cells were treated with dandelion extracts $(2.5 \mathrm{mg} / \mathrm{ml})$ or untreated with drugs. Total RNA extraction was performed at $16 \mathrm{~h}$ after influenza virus infection and the levels of intracellular influenza viral RNA were measured. Influenza viral RNA levels normalized to beta-actin. $\left(^{*} p<0.01\right)$. Mock-infected cells were also analyzed.

(H1N1), which agrees with the simultaneous treatment assay results.

To evaluate the anti-influenza activity after virus infection, we employed the post treatment assay (Figure 3B), quantitative real-time PCR (Figure 4) and minigenome assay (Figure 6) to test the in vitro effect of dandelion extracts on viral replication. Our studies do not show the prevention of receptor binding of the virus after dandelions treatment, but reduction of the nucleoprotein (NP) RNA level and the viral polymerase activity are obvious. Currently, anti-influenza targets include viral factors (such as hemagglutinin (HA), M2 ion channel protein, RNA-dependent RNA polymerase (RdRp), nucleoprotein (NP), non-structural protein (NS) and neuraminidase (NA) and host factors (such as v-ATPase, protease, inosine monophosphate dehydrogenase (IMPDH) and intracellular signalling cascades), and their relevant inhibitors [25]. In virus particles, the genomic RNAs (vRNAs) are associated with the RNAdependent RNA polymerase proteins and the NP, which together form the ribonucleoprotein (RNP) complexes. The NP viral RNA level reflected the RNP complexes's action. Our results indicate that dandelion extracts inhibit influenza virus infection probably by decreasing the NP viral RNA level and viral polymerase activity, and thus affecting the RNP complexes' activities, further to inhibit viral RNA replication.
Vaccines play an important role in combating influenza. However, vaccination has only been able to provide a limited control of the infection, because the virus has a tendency to mutate and thus, escape the immune system. Plants have a long evolutionary history of developing resistance against viruses and have increasingly drawn attention as potential sources of antiviral drugs $[24,26]$. Many plant extracts and compounds of plant origin have been shown to possess activity against influenza viruses. Our results indicate that aqueous dandelion extracts can inhibit influenza virus infections. Dandelion is composed of multiple compounds that are able to regulate multiple targets for a range of medical indications and that are able to be titrated to the specific symptoms of an individual.

\section{Conclusion}

This study has shown that dandelion extracts can inhibit both A/PR/8/34 and WSN (H1N1) influenza viruses by inhibiting viral nucleoprotein synthesis and polymerase activity. These results lead to further investigation about characterization of active compounds and their specific mechanism against influenza virus. Given the urgent need for new and abundantly available anti-influenza drugs, dandelion extracts appear to be a promising option as a replacement or supplemental strategy to currently available anti-influenza therapies. 


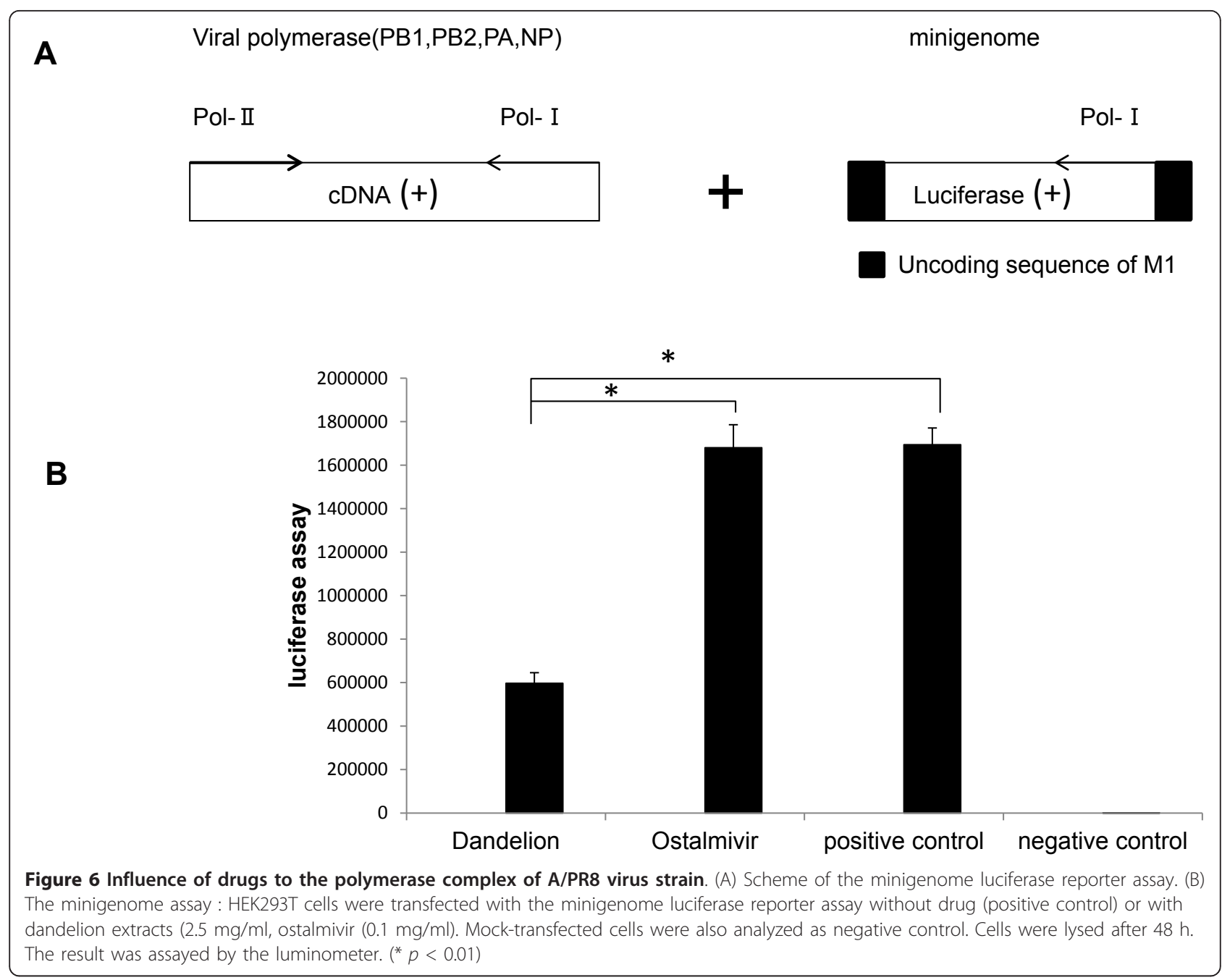

\section{Acknowledgements}

This work was supported by grants 2008ZX10003-012 and 2009ZX10004-305.

\section{Author details}

'CAS Key Laboratory of Pathogenic Microbiology and Immunology (CASPMI), Institute of Microbiology, Chinese Academy of Sciences, 1 Beichen West Road, Beijing 100101, PR China. ${ }^{2}$ Graduate University of Chinese Academy of Sciences, 1 Beichen West Road, Beijing 100101, PR China. ${ }^{3}$ Biochemistry Teaching and Research office of Hebei Medical University, Zhongshan East Road, Shijiazhuang 050017, PR China. ${ }^{4}$ China-Japan Joint Laboratory of Molecular Immunology and Microbiology, Institute of Microbiology, Chinese Academy of Sciences, Beijing, PR China.

\section{Authors' contributions}

Conceived and designed the experiments: WH, BG. Performed the experiments: $W H, H M H, W W$. Contributed reagents/material/analysis tools: BG, WH, HMH, WW. Wrote the paper: WH, BG, HMH. All authors have read and approved the final manuscript.

\section{Competing interests}

The authors declare that they have no competing interests.

Received: 6 August 2011 Accepted: 14 December 2011 Published: 14 December 2011

\section{References}

1. Fouchier RAM, Munster V, Wallensten A, Bestebroer TM, Herfst S, Smith D, Rimmelzwaan GF, Olsen B, Osterhaus ADME: Characterization of a novel influenza a virus hemagglutinin subtype (H16) obtained from blackheaded gulls. J Virol 2005, 79:2814-2822.

2. Webster RG, Guan Y, Krauss S, Shortridge K, Peiris M: Pandemic spread: Influenza. Gene Ther 2001, 8:S1-S1.

3. Boltz DA, Aldridge JR, Webster RG, Govorkova EA: Drugs in Development for Influenza. Drugs 2010, 70:1349-1362.

4. Fleming DM: Managing influenza: amantadine, rimantadine and beyond. Int J Clin Pract 2001, 55:189-195.

5. Cheung $C L$, Rayner JM, Smith GJ, Wang P, Naipospos TS, Zhang J, Yuen KY, Webster RG, Peiris JS, Guan Y, Chen H: Distribution of amantadineresistant H5N1 avian influenza variants in Asia. J Infect Dis 2006 193:1626-1629.

6. Pinto $L H, L a m b$ RA: The $M 2$ proton channels of influenza $A$ and $B$ viruses. J Biol Chem 2006, 281:8997-9000.

7. Hatakeyama S, Kawaoka Y: The molecular basis of resistance to antiinfluenza drugs. Nippon Rinsho 2006, 64:1845-1852.

8. Kiso M, Mitamura K, Sakai-Tagawa Y, Shiraishi K, Kawakami C, Kimura K, Hayden FG, Sugaya N, Kawaoka Y: Resistant influenza A viruses in children treated with oseltamivir: descriptive study. Lancet 2004, 364:759-765.

9. de Jong MD, Tran TT, Truong HK, Vo MH, Smith GJ, Nguyen VC, Bach VC, Phan TQ, Do QH, Guan Y, et al: Oseltamivir resistance during treatment of influenza A (H5N1) infection. N Engl J Med 2005, 353:2667-2672. 
10. Ko HC, Wei BL, Chiou WF: The effect of medicinal plants used in Chinese folk medicine on RANTES secretion by virus-infected human epithelial cells. J Ethnopharmacol 2006, 107:205-210.

11. Mantani N, Andoh T, Kawamata H, Terasawa K, Ochiai H: Inhibitory effect of Ephedrae herba, an oriental traditional medicine, on the growth of influenza A/PR/8 virus in MDCK cells. Antiviral Res 1999, 44:193-200.

12. Hayashi K, Imanishi N, Kashiwayama Y, Kawano A, Terasawa K, Shimada Y, Ochiai $\mathrm{H}$ : Inhibitory effect of cinnamaldehyde, derived from Cinnamomi cortex, on the growth of influenza A/PR/8 virus in vitro and in vivo. Antiviral Res 2007, 74:1-8.

13. Park SJ, Kwon HJ, Kim HH, Yoon SY, Ryu YB, Chang JS, Cho KO, Rho MC, Lee WS: In Vitro inhibitory activity of Alpinia katsumadai extracts against influenza virus infection and hemagglutination. Virol J 2010, 7.

14. Chen CYC, Chang TT, Sun MF, Chen HY, Tsai FJ, Fisher M, Lin JG: Screening from the World's Largest TCM Database Against H1N1 Virus. J Biomol Struct Dyn 2011, 28:773-786.

15. Hudson JB: The use of herbal extracts in the control of influenza. J Med Plants Res 2009, 3:1189-1194.

16. Kuroda K, Sawai R, Shibata T, Gomyou R, Osawa K, Shimizu K: Antiinfluenza virus activity of Chaenomeles sinensis. J Ethnopharmacol 2008, 118:108-112.

17. Ludwig S, Ehrhardt C, Hrincius ER, Korte V, Mazur I, Droebner K, Poetter A, Dreschers S, Schmolke M, Planz O: A polyphenol rich plant extract, CYSTUS052, exerts anti influenza virus activity in cell culture without toxic side effects or the tendency to induce viral resistance. Antiviral Res 2007, 76:38-47.

18. Chu QC, Lin M, Ye JN: Determination of polyphenols in dandelion by capillary zone electrophoresis with amperometric detection. Am Lab 2006, 38:20-+.

19. Sweeney B, Vora M, Ulbricht C, Basch E: Evidence-based systematic review of dandelion (Taraxacum officinale) by natural standard research collaboration. J Herb Pharmacother 2005, 5:79-93.

20. Choi EJ, Kim GH: Dandelion (Taraxacum officinale) Flower Ethanol Extract Inhibits Cell Proliferation and Induces Apoptosis in Human Ovarian Cancer SK-OV-3 Cells. Food Sci Biotechnol 2009, 18:552-555.

21. Hu C, Kitts DD: Antioxidant, prooxidant, and cytotoxic activities of solvent-fractionated dandelion (Taraxacum officinale) flower extracts in vitro. J Agric Food Chem 2003, 51:301-310.

22. Kim JJ, Noh KH, Cho MY, Jang JY, Song YS: Anti-oxidative, antiinflammatory and anti-atherogenic effects of dandelion (Taraxacum officinale) extracts in C57BL/6 mice fed atherogenic diet. Faseb J 2007, 21:A1122-A1122

23. Ovadje P, Chatterjee S, Griffin C, Tran C, Hamm C, Pandey S: Selective induction of apoptosis through activation of caspase-8 in human leukemia cells (Jurkat) by dandelion root extract. J Ethnopharmacol 2011, 133:86-91.

24. Wang YF, Ge H, Xu J, Gu Q, Liu HB, Xiao PG, Zhou JJ, Liu YH, Yang ZR, Su H: Anti-influenza agents from Traditional Chinese Medicine. Nat Prod Rep 2010, 27:1758-1780.

25. Xu WF, Gong JZ, Fang H, Li MY, Liu Y, Yang KH, Liu YZ: Potential Targets and Their Relevant Inhibitors in Anti-influenza Fields. Curr Med Chem 2009, 16:3716-3739.

26. Hsu WL, Chen DY, Shien JH, Tiley L, Chiou SS, Wang SY, Chang TJ, Lee YJ, Chan KW: Curcumin inhibits influenza virus infection and haemagglutination activity. Food Chem 2010, 119:1346-1351.

\section{Submit your next manuscript to BioMed Central and take full advantage of:}

- Convenient online submission

- Thorough peer review

- No space constraints or color figure charges

- Immediate publication on acceptance

- Inclusion in PubMed, CAS, Scopus and Google Scholar

- Research which is freely available for redistribution

Submit your manuscript at www.biomedcentral.com/submit 